\title{
On-line monitoring of citric acid production in solid-state culture by respirometry
}

J. Pintado, ${ }^{a, *}$ B. K. Lonsane, ${ }^{b}$ I. Gaime-Perrau ${ }^{c}$ and S. Roussos ${ }^{c}$

${ }^{a}$ Instituto de lnvestigacions Mariñas (CSIC), rua Eduardo Cabello 6, Vigo 36208,

Galicia, Spain

${ }^{\mathrm{b}}$ Fermentation Technology and Bioengineering Discipline, Central Food Technological Research Institute, Mysore 570013, India

'Laboratoire de Biotechnologie, Centre ORSTOM. 911 Av. Agropolis, B.P. 5045, 34032 Montpellier Cedex 1, France

*To whom correspondence should be addressed.

\section{Abstract}

The aim of this work was to study the possibility of monitoring citric acid production from mussel processing wastes (MPW) by Aspergillus niger in solid-state culture (SSC) on an inert support. This was conducted by measuring $\mathrm{CO}_{2}$ and $\mathrm{O}_{2}$ concentration in exhaust gases, using an automatic sampler connected to a gas chromatograph and a data acquisition system. The procedure permitted information on the physiological state of the culture to be obtained. A relationship between citric acid accumulation and a decrease in $\mathrm{CO}_{2}$ production was found, allowing citric acid production to be followed in real-time. Moreover, respiratory activity $(\mu r)$ can be estimated and the effect of different variables on this parameter studied. Initial nitrogen concentration, a critical factor for achieving high production of citric acid from MPW in submerged culture. revealed no effect in SSC. This indicates a tolerance of SSC to higher concentrations of nitrogen constituting an advantage when using residual media with high levels of protein and variability in their composition.

Keywords: solid-state culture, respirometry, citric acid, mussel processing wastes. Aspergillus niger.

Introduction 
The on-line monitoring of diverse parameters such as $\mathrm{pH}$, nutrient or product concentration presents difficulties in SSC due to characteristics that are inherent to this type of culture, such as the absence of free water and the heterogeneity of solid material [1]. Automatic on-line analysis of $\mathrm{CO}_{2}$ and $\mathrm{O}_{2}$ in the exit gases coming from SSC reactors allows real-time information on the physiological state of the cultures to be obtained and correlation with other parameters such as biomass [2-4] to be established. It is also useful for the monitoring and control of diverse biotransformations [5, 6], and has possible applications to the scale-up of processes [7]. Furthermore, gas measurements in aerobic cultures allow for the calculation of the respiratory activity rate $(\mu r)$ from the natural logarithm of total production of $\mathrm{CO}_{2}$. Since this parameter is obtained from a larger number of data points, a more accurate value of $\mu$ than that calculated from the diverse methods of biomass estimation may be obtained [8].

Citric acid is a primary metabolite whose overproduction and accumulation is due to impaired functioning of the metabolic pathways, conditioned by culture medium composition $[9,10]$. When mycelia pass to the citric acid accumulation phase it is possible to observe a diminution in $\mathrm{CO}_{2}$ production due to: (a) the interruption of the tricarboxylic acid cycle (TCA) at a step previous to decarboxylation; (b) the reuse, in the anaplerotic pathway of oxaloacetate, of $\mathrm{CO}_{2}$ released in pyruvate decarboxylation: and (c) the change from the glucolytic pentose pathway (predominant in the first phase and then inhibited by citrate at the step of gluconate-6P-dehydrogenase), in which a decarboxylation occurs, to the hexoses pathway, in which there is no decarboxylation. This was confirmed by the results obtained by Kubiceck et al. [11] in submerged culture. They showed a stoichiomctric relationship between $\mathrm{CO}_{2}$ fixation and citric acid production which allowed the use of the respirometric technique as an indirect control method. However, there is no report of its application to citric acid production in SSC.

Although, as a primary metabolite, citric acid accumulation is associated with growth, it requires, in order to achieve a high production rate, a deficit of nitrogen which constitutes an obvious growth limiting factor [12]. On the other hand, the amount of carbohydrate utilised for citric acid production assumes direct competition with that directed towards biomass formation. In this respect, previous results obtained in submerged $[13,14]$ and SSC $[14]$ revealed the importance of establishing the adequate 
initial $\mathrm{N}$ level, and its role in submerged fed-batch culture as the regulator of biomass or citric acid production [14].

Citric acid is a possible bioproduct from mussel processing wastes (MPW) developed at the Instituto de Investigacions Mariñas (Vigo, Spain) [15]. Preliminary work [16] using a SSC system composed of an inert support impregnated with media obtained from MPW not only showed better results in a shorter culture time than that in conventional submerged culture [13], but also offered the advantages of SSC [1]. The aim of this work was the application of respirometric control for monitoring citric acid production. In addition, the effect of the initial nitrogen concentration of the medium in these systems was studied.

Materials and methods

Micro-organism and inoculum preparation

Aspergillus niger (CBS 554-65) was maintained on malt-yeast extract slants at $4^{\circ} \mathrm{C}$ by subculturing every month. For inoculum preparation [17], a PDA medium, with pH adjusted to 6, was prepared and $40 \mathrm{ml}$ placed in Erlenmeyer flasks of $250 \mathrm{ml}$ and autoclaved at $120^{\circ}$, for $20 \mathrm{~min}$. The spores produced on the slant at $30^{\circ} \mathrm{C}$ for 7 days were collected and inoculated into melted medium cooled to about $45^{\circ} \mathrm{C}$. The wellmixed inoculated medium was allowed to solidify undisturbed. The growth and sporulation of the culture took place at $30^{\circ} \mathrm{C}$. After 5 days of incubation the spores were harvested by adding five parts of sterilized $0.01 \%$ Tween 80 solution and magnetic stirring. In the case of cultures with MPW medium, the suspension of spores was prepared directly in the culture medium. The spore density was adjusted to result in an initial concentration of $2 \times 10^{7}$ spores/g of initial dry matter (IDM).

Culture media and conditions

MPW medium [16] was prepared by concentration and total saccharification of raw mussel processing effluents as described previously [18]. It was supplemented with glycine and $\mathrm{KH}_{2} \mathrm{PO}_{4}$ to the initial concentration of nitrogen and phosphorus optimized for citric acid production in SSC in a previous work [14]: glucose 100g/litre; total 
nitrogen (proteinous nature 95\%) $1.42 \mathrm{~g}$ /litre (with a fraction, 0.22, that cannot be used by the A. niger strain employed [14]); total phosphorus $0.14 \mathrm{~g} /$ litre and a metal content of Fe, Mn, Zn, Cu and Mg, 1.68, 0-22, 1.17, 0.52 and 17.75 mg/litre, respectively.

Basic synthetic medium ( $/ \mathrm{N}$ : 35) was prepared to be as similar as possible to the MPW medium composition: glucose $100 \mathrm{~g} /$ litre; glycine $6.44 \mathrm{~g} /$ litre (total nitrogen $1.20 \mathrm{~g} /$ litre); $\mathrm{KH}_{2} \mathrm{PO}_{4} 0.62 \mathrm{~g} /$ litre (total phosphorus 0.14g/litre); $\mathrm{FeSO}_{4} \cdot 7 \mathrm{H}_{2} 0$ 10.5mg/litre (Fe 2.10 $\mathrm{mg} / \mathrm{litre}$ ); $\mathrm{MgSO}_{4} \cdot 7 \mathrm{H}_{2} 0180 \mathrm{mg} / \mathrm{litre}$ (Mg $17.75 \mathrm{mg} / \mathrm{litre}$ ). For medium with a high nitrogen concentration $(\mathrm{C} / \mathrm{N}: 15)$ the concentration of glycine was $16.14 \mathrm{~g} /$ litre (total nitrogen $3.01 \mathrm{~g} /$ /itre). Both media were prepared concentrated to result in the composition described, following volume inoculum addition. The $\mathrm{pH}$ of the media was adjusted to 4.5 .

Sugarcane bagasse, with 0.8-2.0 mm particle diameter range and exhaustively washed with distilled water, was used as a support $[4,8]$ absorbing the nutrient medium at a ratio of 17:67 and sterilised by steaming for $1 \mathrm{~h}$. Inoculum, prepared as described above, was added and mixed using aseptic conditions. The resulting initial moisture content was $73 \%$. Cultures were performed in a series of column incubators, using a system described previously [19], loaded with about $35 \mathrm{~g}$ of moist solid medium and incubated at $30^{\circ} \mathrm{C}$ with an aeration rate of 2 litre/h.

Sample treatment

The whole content of the column incubator was weighed and homogenized to obtain samples for analysis. Moisture content was determined gravimetrically from $5 \mathrm{~g}$ of material. Analytical determinations were carried out on the water extract of the suspension of $5 \mathrm{~g}$ of fresh material in $45 \mathrm{ml}$ of distilled water, after mixing and filtration using a Millipore filter $(0.45 \mu \mathrm{m})$.

Analytical techniques

Glucose and citric acid concentrations were analysed by HPLC (Biorad Aminex HPX 87H; mobile phase: $\mathrm{H}_{2} \mathrm{SO}_{4} 6 \mathrm{mmol}$; flow: $0.8 \mathrm{ml} / \mathrm{min}$; $\mathrm{T}: 65^{\circ} \mathrm{C}$ ). Total nitrogen and phosphorus were analysed, after Kjeldahl digestion of samples, by Flow Injection 
Analysis (FIA), using a Lachat Quick Chem ${ }^{\circledR} 4200$ analyser (Milwaukee, USA) and QuickChem ${ }^{\circledR}$ methods TKN 10-107-06-2-E (based on the salicilate-isocianurate method) and TKP 10-115-01-1-C (based on the reaction with ammonium phosphomolybdate), respectively.

System for $\mathrm{CO}_{2}$ and $\mathrm{O}_{2}$ analysis in exhaust air

The system, described previously [8], samples automatically (Sampler B.C.V., 8, Delsi, France) the exhaust air from the incubators, previously dried by passing through silica gel tubes. $\mathrm{CO}_{2}$ and $\mathrm{O}_{2}$ are separated and measured by a gas chromatograph with an automatic injector and a thermal conductivity detector (Model IGC 11, Delsi, France), equipped with a gas separating concentric column (CTRI, Alltech, USA) and connected to a data acquisition system. An integrator program (Chroma, Biosystèmes, France) controls the whole monitoring system.

Results and discussion

The solid-state culture system using MPW medium and sugarcane bagasse as inert support in aireated reactors was tested but given the limited availability of MPW at ORSTOM (France), a synthetic media, prepared as similarly as possible to MPW (with $\mathrm{C} / \mathrm{N}$ 35) was also used and the results compared with those obtained with MPW.

Citric acid production using the synthetic medium was slightly lower than that with the MPW medium (Fig. 1), possibly due to the presence of other micronutrients in the MPW medium. The kinetics in both media were very similar and the synthetic media were used in subsequent work.

Relation between $\mathrm{CO}_{2}$ production and other parameters

The monitoring of the different parameters in the culture with synthetic medium allowed two phases to be distinguished (Fig. 2).

In the first phase the rapid growth of the fungus took place, reflected by the exponential kinetics of $\mathrm{CO}_{2}$ production as well as the consumption of $\mathrm{N}$ and $\mathrm{P}$. 
The second phase started at about $16 \mathrm{~h}$ of incubation with the interruption of nitrogen consumption and a change in the slope of phosphorus uptake. It should be noted that this occurred without total exhaustion of either nutrient (total initial $\mathrm{N}$ and $\mathrm{P}$ were 364 and $47 \mathrm{rag} / 100 \mathrm{~g}$ of IDM, respectively). These changes coincided with the initiation of citric acid accumulation and a decrease in the emission of $\mathrm{CO}_{2}$ that then remained almost constant. Nevertheless, the slope of glucose consumption continued to be constant throughout the culture.

Relationship with the physiological state of the culture

The microscopic observation of the culture allowed the evolution of A. niger mycelial morphology to be followed and this could be related to other parameters. The detection of measurable quantities of $\mathrm{CO}_{2}$ started with the germination of spores which occurred at about $10 \mathrm{~h}$ of culture. The interruption in the uptake of $\mathrm{N}$ and $\mathrm{P}$, the initiation of the accumulation of the acid and the decline in the production of $\mathrm{CO}_{2}$, that occurred around 15h, coincided with the onset of mycelial branching. Sporulation took place after approximately $23 \mathrm{~h}$ of culture and did not affect in any way citric acid production or glucose consumption, which maintained the same slopes.

Validity of respirometry for monitoring SSC

The fact that the concentration of $\mathrm{CO}_{2}$ reflects other parameters whose on-line measurement is difficult, confirms that respirometry constitutes an interesting technique for monitoring the evolution of cultures. It allows the actual time at which accumulation of citric acid occurs to be observed.

Nevertheless some aspects, such as the interruption of the uptake of $\mathrm{N}$ and $\mathrm{P}$, could not be explained. Previous results in submerged culture showed that this strain required $\mathrm{N}$ and $\mathrm{P}$ limiting media in order to achieve high citric acid production [13]. The interruption of the uptake of $\mathrm{N}$ was due to the exhaustion of the available nitrogen in the culture medium, a fact considered responsible for the shift from a growing mycelium to a carbon accumulating and citric acid producing mycelium at a lower growth rate [20]. The uptake of phosphorus always appeared to be coupled with the uptake of nitrogen, 
with interactions between the initial levels of both nutrients [13]. However, in this system, limitation of $\mathrm{N}$ and $\mathrm{P}$ does not seem to be the factor that promotes citric acid accumulation.

Respiratory activity at different $\mathrm{C} / \mathrm{N}$ ratios

In order to study by respirometry the different fungal behaviour determined by the concentration of nitrogen in the culture medium, two different ratios of $\mathrm{C} / \mathrm{N}$ in the initial medium were tested: 15 and 35. The composition of the other nutrients was held constant and nitrogen was added as described previously.

The results (Fig. 3) showed that the initial level of nitrogen did not exert a noteworthy effect on this system, registering a very similar evolution of all culture parameters in both $\mathrm{C} / \mathrm{N}$ ratios. It must be noted that the levels and kinetics of nitrogen and phosphorus consumption were similar. In addition, citric acid and $\mathrm{CO}_{2}$ production levels were similar in both cases. The estimation of the respiratory activity, calculated according to Saucedo-Castañeda et al. [8], shows similar values for the two conditions tested (Fig. 4).

The fungal behaviour appears to differ from the previous results obtained with the same strain in submerged culture [13], in which under an even more severe phosphate limitation, citric acid production was inversely related to the nitrogen content of the culture medium. Similar results were obtained by Dawson et al. [21]. These authors also observed that an increase in nitrogen concentration was followed by increased sugar consumption and suggested that it could be converted to storage carbohydrates or $\mathrm{CO}_{2}$. This contradicts the results in solid-state culture presented here.

The interpretation of the different effects of nitrogen on solid-state and submerged culture may be related to the explanation of Shankaranand \& Lonsane [22] concerning both the appearance of gradients inside the cultures and the lower rate of transfer of nutrients that cofavour SSC systems. These would diminish the inhibitory effect of some nutrients, such as metals, nitrogen or phosphorus, in the case of citric acid production. The comparison with previous results obtained, with the same strain and MPW media, in submerged culture [13] and in SSC on polyurethane foam $[14,16]$, suggests a less pronounced effect of this variable towards a system with less water 
availability. It should be noted that the polyurethane foams used are hydrophobic and so water retention is weaker than that in bagasse.

From a practical point of view, the lower sensitivity of the system to an excess of nutrients with an inhibitory effect is an interesting advantage, even more so when byproduct materials such as MPW are used. This would avoid the necessity of MPW pretreatment in order to reduce the content of the above mentioned deletereous nutrients, and would provide higher stability to the results, in view of the likely variations in the composition of the effluents.

\section{Acknowledgements}

J. Pintado thanks the Galician Government, Xunta de Galicia, for a research grant and ORSTOM (Montpellier, France) for facilities.

\section{References}

1. Mitchel. D. A. \& Lonsane, B. K., Definition, characteristics and potential. In: Solid Substrate Cultivation, eds H. W. Doelle, D. A. Mitchel and C. E. Rolz, pp. 1-16. Elsevier, Barking, 1992.

2. Sato, K., Nagatani, M., Nakamura, K. and Sato, S., Growth estimation of Candida lipolytica from oxygen uptake in a solid state culture with forced aeration. J. Ferment. Technol. 1983, 61, 623-629.

3. Nishio, N., Tai, K. and Nagai, S., Hydrolase production by Aspergillus niger in solid state cultivation. Europ. J. Appl. Microbiol. Biotechnol. 1979, 8, 263-270.

4. Oriol, E., Schettino, B. G., Viniegra, G. and Raimbault, M., Solid-state culture of Aspergillus niger on support. J. Ferment. Technol 1988, 66, 57-62.

5. Trejo-Hernandez, M. R., Raimbault, M., Roussos, S. and Lonsane, B. K., Potential of solid state fermentation for production of ergot alkaloids. Letters Appl. Microbiol. 1992, 15, 156-159.

6. Saucedo-Castañeda, G., Lonsane, B. K., Navarro, J. M., Roussos, S. and Raimbault, M., Potential of using a single fermenter for biomass build-up, starch hydrolysis, and ethanol production. Appl. Biochem. Biotechnol. 1992, 36, 47-61. 
7. Lonsane, B. K., Saucedo-Castañeda, G., Raimbault, M., Roussos, S., ViniegraGonzalez, G., Ghildyal, N. P., Ramakrishna, M. and Krishnaiah, M. M., Scale-up strategies for solid state fermentation systems. Proc. Biochem. 1992, 27, 259-273.

8. Saucedo-Castañeda, G., Trejo-Hernandez, M. R., Lonsane, B. K., Navarro, J. M., Roussos, S., Dufour, D. and Raimbault, M., On line automated monitoring and control systems for $\mathrm{CO}_{2}$ and $\mathrm{O}_{2}$ in aerobic and anaerobic solid-state fermentations. Proc. Biochem. 1994, 29, 13-24.

9. Kubicek, C. P. and Rhor, M., Citric acid fermentation. CRC Critical Rev. Biotechnol. 1986, 3, 331-373.

10. Legisa, M., Jerneje, K. and Cimerman, A., New aspects of citric acid accumulation in Aspergillus niger. Biopractice 1992, 1, 44-48.

11. Kubicek, C. P., Zehentaruber, O. and Röhr, M., An indirect method for studying the fine control of citric acid formation by Aspergillus niger. Biotechnol. Lett. 1979, 1, 47-52.

12. Kristiansen, B. and Sinclair, C. G., Production of citric acid in batch culture. Biotechnol. Bioeng. 1978, 20, 1711-1722.

13. Pintado, J., Murado, M. A., Gonzalez, M. P., Miron, J. and Pastrana, L., Joint effect of nitrogen and phosphorus concentrations on citric acid production by different strains of Aspergillus niger grown on an effluent. Biotechnol. Lett. 1993, 15, 11571162.

14. Pintado, J., Produccion de acido citrico a partir de efluentes del procesado de mejillon. Modalidades de cultivo y criterios de optimizaci6n. Ph. D. thesis. Universidad de Santiago de Compostela, Spain, 1995.

15. Murado, M. A., Gonzalez, M. P. \& Pastrana, L., Mussel processing wastes as a fermentation substrate. In Fisheries Processing, ed. A. M. Martin, pp. 311-343. Chapman and Hail, London, 1994.

16. Pintado, J., Torrado, A., Miron, J., Montemayor, I., Gonzalez, P., Murado, M. and Samroman, A., Citric acid production from mussel processing wastes in solid state culture. Med. Fac. Landbouww. Univ. Gent. 1994, 59, 2429-2437.

17. Roussos, S., Olmos, A., Raimbault, M., Saucedo-Castañeda, G. and Lonsane, B. K., Strategies for large scale inoculum development for solid state fermentation system: conidiospores of Trichoderma harzianum. Biotechnol. Techniques 1991, 5, 415-420. 
18. Murado, M. A., Gonzalez, M. P., Pastrana, L., Siso, M. I. G., Miron, J. and Montemayor, M. I., Enhancement of the bioproduction potential of an amylaceous effluent. Bioresource Technol. 1993, 44, 155-163.

19. Raimbault, M. and Alazard, D., Culture method to study fungal growth in solid fermentation. Europ. J. Appl. Microbiol. Biotechnol. 1980, 9, 199-209.

20. Kristiansen, B. and Sinclair, C. G., Production of citric acid in continuous culture. Biotechnol. Bioeng. 1979, 21,297-315.

21. Dawson, M. W., Maddox, I. S. and Brooks, J. D., Evidence for nitrogen catabolite repression during citric acid production by Aspergillus niger under phosphatelimited growth conditions. Biotechnol. Bioeng. 1989, 33, 1500-1504.

22. Shankaranand, V. S. and Lonsane, B. K., Coffee husk -- an inexpensive substrate for production of citric acid by Aspergillus niger in a solid-state fermentation system. World J. Microbiol. Biotechno. 1994, 10, 165-168. 
Fig. 1. Comparison between cultures of A. niger grown, at $30^{\circ} \mathrm{C}$ in SSC with bagasse as inert support imbibed with mussel processing wastes medium (MPW) and on a synthetic medium (S) with equivalent nutrient composition (see text). CIT: citric acid; G: glucose; IDM: initial dry matter.

Fig. 2. Time course of A. niger grown, at $30^{\circ} \mathrm{C}$ in SSC with bagasse as inert support, imbibed with a synthetic medium with a C:N ratio of 35. CIT: citric acid: G: glucose; $\mathrm{P}_{\mathrm{tc}}$ : total phosphorus consumed; $\mathrm{N}_{\mathrm{tc}}$ : total nitrogen consumed: IDM: initial dry matter

Fig. 3. Effect of carbon:nitrogen ratio of the nutritive solution (black symbols: C:N = 15; white symbols: $\mathrm{C}: \mathrm{N}=35$ ) imbibed in sugarcane bagasse, on A. niger grown at $30^{\circ} \mathrm{C}$, on the evolution of different culture parameters. $\mathrm{RH}$ : relative humidity; other notations as for Fig. 2.

Fig. 4. Effects of initial nitrogen concentration in the nutritional media on the evolution of respirometric parameters of A. niger grown at $30^{\circ} \mathrm{C}$ in SSC with sugarcane bagasse as inert support (black symbols: $\mathrm{C}: \mathrm{N}=15$; white symbols: $\mathrm{C}: \mathrm{N}=35$ ). $\mathrm{A}: \mathrm{CO}_{2}$ and $\mathrm{O}_{2}$ evolution rate. B: Total amount of $\mathrm{CO}_{2}$ and $\mathrm{O}_{2}$ produced. C: Estimation of respiratory activity ( $\mu r)$ through $\mathrm{CO}_{2}$ measurement. 